\title{
Influence of afatinib dose on outcomes of advanced EGFR-mutant NSCLC patients with brain metastases
}

\author{
Wan-Ling Tan', Quan Sing Ng${ }^{1}$, Cindy Lim², Eng Huat Tan ${ }^{1}$, Chee Keong Toh ${ }^{1}$, Mei-Kim Ang ${ }^{1}$, \\ Ravindran Kanesvaran ${ }^{1}$, Amit Jain ${ }^{1}$, Daniel S. W. Tan ${ }^{1,3}$ and Darren Wan-Teck Lim ${ }^{1,4^{*}}$ (D)
}

\begin{abstract}
Background: Afatinib is an oral irreversible epidermal growth factor receptor (EGFR) tyrosine-kinase inhibitor (TKI) indicated in first-line treatment of advanced EGFR-mutant (EGFRm+) non-small cell lung cancer (NSCLC). Dose dependent side effects can limit drug exposure, which may impact on extracranial and central nervous system (CNS) disease control.

Methods: We performed a retrospective study of 125 patients diagnosed with advanced EGFRm+ NSCLC treated with first-line afatinib at a tertiary Asian cancer center, exploring clinicopathological factors that may influence survival outcomes. Median progression free survival (PFS) was estimated using the Kaplan-Meier method. Comparison of PFS between subgroups of patients was done using log-rank tests and Cox proportional hazards models.

Results: Out of 125 patients, 62 (49.6\%) started on $40 \mathrm{mg}$ once daily (OD) afatinib, 61 (48.8\%) on $30 \mathrm{mg}$ OD and $1(0.8 \%)$ on $20 \mathrm{mg}$ OD. After median follow-up of 13.8 months from afatinib initiation, the observed response rate was $70.4 \%$ and median PFS 11.9 months (95\% Cl 10.3-19.3). 42 (33.6\%) patients had baseline brain metastases (BM) and PFS of those who started on $40 \mathrm{mg}$ OD $(n=17)$ vs. $30 \mathrm{mg}$ OD $(n=25)$ was 13.3 months vs. 5.3 months (HR 0.39, 95\% Cl 0.15-0.99). BM+ patients who started on $40 \mathrm{mg}$ had similar PFS to patients with no BM (13.3 months vs. 15.0 months; HR 0.79, 95\% Cl 0.34-1.80).

Conclusion: In patients with advanced EGFRm+ NSCLC with BM+, initiating patients on afatinib $40 \mathrm{mg} O D$ was associated with improved PFS compared to $30 \mathrm{mg} \mathrm{OD}$, underscoring the potential importance of dose intensity in control of CNS disease.
\end{abstract}

Keywords: EGFR mutation NSCLC, Metastatic, Afatinib, Brain metastases, Dose

\section{Background}

Epidermal growth factor receptor (EGFR) tyrosine kinase inhibitors (TKIs) are the standard of care for first-line treatment of advanced NSCLC with sensitizing EGFR mutations $[1,2]$. Despite high response rates of $60-70 \%$, treatment failure inevitably ensues after a median duration of 10-18 months, regardless of choice of TKI. Although the emergence of genomic alterations commonly accounts

\footnotetext{
* Correspondence: darren.lim.w.t@singhealth.com.sg

${ }^{1}$ Division of Medical Oncology, National Cancer Centre Singapore, Singapore, Singapore

${ }^{4}$ Institute of Molecular and Cell Biology, A*STAR, Singapore, Singapore Full list of author information is available at the end of the article
}

for secondary resistance to EGFR TKI, CNS failure is often attributed to inadequate penetration into the CNS regarded as a 'sanctuary' site. Indeed, the lifetime risk of brain metastases (BM) is more than $30 \%$ of patients in EGFR mutant NSCLC, and where present, has traditionally been associated with poorer survival [3-5].

Although intracranial efficacy of first-line EGFR TKIs has not been established in prospective large-scale studies, clinical observations from trials support intracranial activity with afatinib - a second-generation, irreversible pan-human epidermal growth factor receptor (HER) inhibitor. In a combined post-hoc analysis on patients with asymptomatic baseline BM from the LUX-lung 3 and

(c) The Author(s). 2018 Open Access This article is distributed under the terms of the Creative Commons Attribution 4.0 International License (http://creativecommons.org/licenses/by/4.0/), which permits unrestricted use, distribution, and reproduction in any medium, provided you give appropriate credit to the original author(s) and the source, provide a link to the Creative Commons license, and indicate if changes were made. The Creative Commons Public Domain Dedication waiver (http://creativecommons.org/publicdomain/zero/1.0/) applies to the data made available in this article, unless otherwise stated. 
LUX-lung 6 studies, afatinib significantly improved the objective response rate (RR) and progression-free survival (PFS) compared to chemotherapy $[3,6]$. However, due to potent EGFR wild-type inhibition, afatinib is associated with increased skin and gastrointestinal toxicities, resulting in dose reductions reported in up to 53.3 and $28 \%$ patients in the randomized LUX-Lung 3 and 6 trials respectively [7]. The potential impact of dose reductions with afatinib on CNS disease control also remains poorly characterized.

We performed a retrospective study to evaluate the clinicopathological factors affecting survival outcomes of patients with EGFRm+ NSCLC treated with first-line afatinib, specifically examining the impact of starting dose in patients with or without BM at diagnosis.

\section{Methods}

\section{Study population}

We retrospectively analyzed 125 consecutive patients with advanced/stage IV EGFRm+ NSCLC treated with first-line afatinib between January 2012 to February 2017 at the National Cancer Centre Singapore (NCCS) and consented to data collection for research purposes. We included eligible patients under our Lung Cancer Consortium Singapore (LCCS) data-base up to February 2017. Patients were analyzed for RR and PFS as per investigator-assessed Response Evaluation Criteria in Solid Tumors (RECIST 1.1) criteria. After initiation of afatinib, radiological assessments of patients were performed at 2-3 month intervals as decided by the treating physician, with brain imaging by either contrasted computed tomography $(\mathrm{CT})$ or magnetic resonance imaging (MRI) brain performed regularly for patients with documented brain metastases. An exploratory analysis was done for clinical factors that influenced survival. Reflex EGFR mutational analysis was performed by direct Sanger sequencing or Roche COBAS EGFR mutation test v2 [8-11]. This research was approved by our local Centralized Institutional Review Board (CIRB) and data was collected and subsequently analyzed anonymously prior to reporting.

\section{Statistical analysis}

PFS was defined as time from start of afatinib treatment to progression or death. Median PFS was estimated using the Kaplan-Meier method. Comparison of PFS between subgroups of patients was done using log-rank tests and Cox proportional hazards models. Two-sided $p$-values less than 0.05 were considered statistically significant. All analyses were performed in Stata (Version 14.2, StataCorp, Texas, USA).

\section{Results}

Clinico-pathologic characteristics

The baseline characteristics of the 125 patients with EGFRm+ lung cancer who received first-line afatinib are summarized in Table 1 . The median age at diagnosis was 62 years (range 26-86) and 121 (96.8\%) had adenocarcinoma. 87 (69.6\%) patients had EGFR exon 19 deletion, 27 (21.6\%) had L858R mutation, and the rest (8.8\%) had

Table 1 Patient Baseline Characteristics. The baseline demographics and clinical characteristics of patients with advanced EGFRm + NSCLC treated with first-line afatinib $(n=125)$ in our cohort

\begin{tabular}{|c|c|c|}
\hline Characteristic & No. & $\%$ \\
\hline \multicolumn{3}{|l|}{ Sex } \\
\hline Male & 64 & 51.2 \\
\hline Female & 61 & 48.8 \\
\hline \multicolumn{3}{|l|}{ Age at diagnosis, years } \\
\hline Median & 62 & \\
\hline Range & $26-86$ & \\
\hline \multicolumn{3}{|l|}{ Ethnicity } \\
\hline Chinese & 100 & 80.0 \\
\hline Malay & 14 & 11.2 \\
\hline Indian & 3 & 2.4 \\
\hline Others & 8 & 6.4 \\
\hline \multicolumn{3}{|l|}{ Smoking status } \\
\hline Never & 95 & 76.0 \\
\hline Former & 17 & 13.6 \\
\hline Current & 13 & 10.4 \\
\hline \multicolumn{3}{|l|}{ Histotype - NSCLC } \\
\hline Adenocarcinoma & 121 & 96.8 \\
\hline Adenosquamous carcinoma & 1 & 0.8 \\
\hline NOS & 3 & 2.4 \\
\hline \multicolumn{3}{|l|}{ EGFR mutation type } \\
\hline Exon 19 deletion ${ }^{[a]}$ & 87 & 69.6 \\
\hline Exon 21 L858R & 27 & 21.6 \\
\hline Others $^{[b]}$ & 11 & 8.8 \\
\hline \multicolumn{3}{|l|}{ Brain metastases at baseline } \\
\hline No & 82 & 65.6 \\
\hline Yes & 42 & 33.6 \\
\hline Unknown & 1 & 0.8 \\
\hline \multicolumn{3}{|c|}{ Starting dose of afatinib once daily (OD) } \\
\hline $40 \mathrm{mg}$ & 62 & 49.6 \\
\hline $0 \mathrm{mg}$ & 61 & 48.8 \\
\hline $0 \mathrm{mg}$ & 1 & 0.8 \\
\hline Unknown & 1 & 0.8 \\
\hline
\end{tabular}

${ }^{[a]}$ E746_A750del; E746_A750delinsIP; E746_A750delinsQP; E746_A750delinsVP; E746_T751delinsV; E746_S752delinsV; E746_P753delinsVS; L747_A750delinsP; L747_T751del; L747_P753delinsS; NOS

${ }^{[b]}$ E697Q; A763 Y764insFQEA; Double mutation; Unknown NSCLC Non-small cell lung cancer, NOS Not otherwise specified 
other EGFR mutations including G719A, E697Q, exon 20 mutations like A763_Y764insFQEA, double mutations or unknown. 95 (76.0\%) patients were neversmokers and the remaining were former/current smokers. Of note, $42(33.6 \%)$ patients had BM prior to afatinib initiation. 62 (49.6\%) started on $40 \mathrm{mg}$ once daily (OD) afatinib, 61 (48.8\%) on $30 \mathrm{mg}$ OD and 1 (0.8\%) on $20 \mathrm{mg}$ OD at the treating physician's discretion, due to concerns about drug tolerability.

\section{Factors influencing outcomes to afatinib}

Median follow-up time was 13.8 months (95\% CI 11.5 to 19.5 months) from start of afatinib treatment. Median duration of afatinib treatment was 8.7 months. At the time of data analysis in February 2017, 52 patients (41.6\%) were still on afatinib. RR with afatinib was $70.4 \%$ and the disease control rate was $77.6 \%$. No complete response (CR) was seen, while $11.2 \%$ had progressive disease (PD) as best overall RECIST response. The median PFS was 11.9 months (95\% CI 10.3 to 19.3 months). Table 2 summarizes the clinical factors influencing PFS outcomes to afatinib in the total population by univariate analysis. Smoking history and EGFR mutation type were statistically significant clinical factors associated with PFS (log-rank $p=0.017$ and $<0.001$, respectively). Interestingly, in patients with brain metastases, a lower starting dose was found to have a detrimental effect on outcomes.

\section{Characteristics of patients with brain metastasis initiated on $30 \mathrm{mg}$ vs. $40 \mathrm{mg}$}

We further analyzed the 42 patients with BM prior to afatinib initiation. 25 (59.5\%) of them were started on $30 \mathrm{mg}$ afatinib daily and 17 (40.5\%) started on $40 \mathrm{mg}$. There were no significant differences between the 2 groups (40 mg vs $30 \mathrm{mg}$ OD) for important clinical characteristics such as ECOG status, age and smoking history (Table 3 ). There was greater proportion of females in the $30 \mathrm{mg}$ group $(n=16 / 25,64.0 \%)$ compared to 40 mg group $(n=6 / 11,35.3 \%)$, but the difference was not statistically significant $(p=0.067)$. Of the $42 \mathrm{BM}+$ patients, 26 had upfront cranial irradiation due to symptomatic or multiple BM with mass effect. Patients who started on $40 \mathrm{mg}$ were more likely to have undergone whole brain radiotherapy (WBRT) prior to afatinib compared to those started on $30 \mathrm{mg}$ ( $n=14 / 17,82.4 \%$ vs $n=12 / 25,48 \%, p=0.024$ ) for symptomatic BM (Table $3)$. However, on further analysis to explore the effects of WBRT pre-afatinib, we found that starting dose remained significantly associated with PFS amongst patients who had cranial irradiation pre-afatinib, and in multivariable analysis adjusting for WBRT (Table 4). At time of $\mathrm{PD}$, most patients who started on $30 \mathrm{mg}$ were still on the same dose (81.8\%), whereas most of the 40 mg patients had dose reductions (70\%) (Fig. 1).

\section{Influence of starting dose on outcomes in patients with brain metastases}

We next formally explored the interaction between BM and afatinib starting dose (Table 5 and Fig. 2). Amongst patients with BM, median PFS for those who received starting dose $40 \mathrm{mg} O D$ vs. $30 \mathrm{mg}$ OD was 13.3 vs. 5.3 months (HR 0.39, 95\% CI 0.15-0.99) (Table 2). However, for patients with no BM at start of afatinib, $40 \mathrm{mg}$ starting dose had no significant impact on median PFS compared to $30 \mathrm{mg}$ (HR 0.95, 95\% CI 0.44-2.04). 21/42 BM+ patients had documented PD on afatinib and 1 patient (30 mg group) had both CNS and extracranial/systemic progression at time of PD. For site of first progression, patients who started on $40 \mathrm{mg}$ were less likely to have CNS progression than those on $30 \mathrm{mg}$ (30\% vs $63.6 \%$, $p=0.198$ ) (Fig. 1), although this was not statistically significant due to the small numbers. Of note, patients with BM who started on $40 \mathrm{mg}$ had similar PFS to patients with no BM (13.3 months vs. 15.0 months; HR 0.79, 95\% CI 0.34-1.80). Similar results were obtained when this analysis was repeated in the subset of never-smokers with exon 19 deletions or L858R mutations (Table 5).

\section{Discussion}

In this retrospective analysis, we demonstrated clinical efficacy of afatinib in patients with EGFRm+ NSCLC consistent with large-scale randomized trials [12, 13], with worse outcome in patients with prior smoking histories. However, we did not identify the presence of BM as a negative prognostic factor, prompting us to further examine the patient characteristics and dosing profiles. Interestingly, we found that $\mathrm{BM}+$ patients who commenced on afatinib $40 \mathrm{mg}$ OD had better outcomes than those started on $30 \mathrm{mg}$ OD (median PFS 5.3 vs 13.3 months, $p=0.041$ ), and comparable to that of patients without BM (Fig. 2).

While first-line afatinib starting dose of $30 \mathrm{mg}$ OD has been previously reported to have similar clinical efficacy as $40 \mathrm{mg}$ OD and better tolerated in patients with EGFRm + NSCLC [14], the effect of starting dose on BM has not been studied. In the post-hoc analyses of LUX-Lung 3 and 6 trials reported by Yang and colleagues [7], PFS of patients on afatinib reduced to 30 $\mathrm{mg} /$ day due to adverse events was found to be similar to those remaining on $40 \mathrm{mg} /$ day. Although the authors concluded that dose adjustment of afatinib improved incidence of adverse events without compromising on therapeutic efficacy, such effect of afatinib dosing was not examined specifically in the subset of patients with brain metastases. Whereas in our study, we had 
Table 2 Factors influencing outcomes to afatinib. The clinical factors that influenced PFS in our cohort

\begin{tabular}{|c|c|c|c|c|c|}
\hline & No. of events/ patients & Median PFS, months (95\% Cl) & Log-rank p-value & Hazard ratio $(95 \% \mathrm{Cl})$ & Cox model $p$-value \\
\hline Total & $60 / 120$ & $11.9(10.3,19.3)$ & NA & NA & NA \\
\hline \multicolumn{6}{|l|}{ Sex } \\
\hline Male & $35 / 62$ & $13.3(9.0,20.1)$ & 0.344 & 1 & 0.343 \\
\hline Female & $25 / 58$ & $11.9(10.3,25.7)$ & & $0.78(0.47,1.31)$ & \\
\hline \multicolumn{6}{|c|}{ Age at diagnosis, years } \\
\hline$<65$ & $45 / 86$ & $11.9(9.7,19.3)$ & 0.791 & 1 & 0.790 \\
\hline$\geq 65$ & $15 / 34$ & $11.7(5.3, U D)$ & & $0.92(0.51,1.66)$ & \\
\hline \multicolumn{6}{|l|}{ Smoking history } \\
\hline Never & $42 / 91$ & $14.5(10.7,22.1)$ & 0.017 & 1 & 0.025 \\
\hline Former / Current & $18 / 29$ & $7.9(3.5,17.4)$ & & $1.94(1.12,3.38)$ & \\
\hline \multicolumn{6}{|l|}{ EGFR mutation type } \\
\hline Exon 19 deletion & $40 / 83$ & $15.0(10.9,22.1)$ & $<0.001$ & 1 & 0.008 \\
\hline L858R & $12 / 27$ & $11.2(6.5, \mathrm{UD})$ & & $1.19(0.62,2.28)$ & \\
\hline Others & $6 / 8$ & $4.5(1.7, \mathrm{UD})$ & & $5.51(2.23,13.64)$ & \\
\hline \multicolumn{6}{|c|}{ Brain metastasis at start of afatinib } \\
\hline No & $40 / 80$ & $15.0(10.9,20.6)$ & 0.140 & 1 & 0.153 \\
\hline Yes & $20 / 40$ & $7.9(5.1,13.3)$ & & $1.50(0.87,2.57)^{a}$ & \\
\hline \multicolumn{6}{|l|}{ Starting dose $e^{b}$} \\
\hline 30 mg & $23 / 58$ & $10.7(6.5, U D)$ & 0.105 & 1 & 0.113 \\
\hline $40 \mathrm{mg}$ & $37 / 61$ & $15.0(10.8,20.6)$ & & $0.63(0.36,1.11)$ & \\
\hline \multicolumn{6}{|c|}{ Amongst patients with no brain metastasis: } \\
\hline \multicolumn{6}{|c|}{ Starting dose $e^{\mathrm{b}}$} \\
\hline 30 mg & $10 / 35$ & UD & 0.897 & 1 & 0.898 \\
\hline $40 \mathrm{mg}$ & $30 / 44$ & $15.0(10.8,22.1)$ & & $0.95(0.44,2.04)$ & \\
\hline \multicolumn{6}{|c|}{ Amongst patients with brain metastasis: } \\
\hline \multicolumn{6}{|l|}{ Starting dose } \\
\hline $30 \mathrm{mg}$ & $13 / 23$ & $5.3(3.1,10.7)$ & 0.040 & 1 & 0.041 \\
\hline $40 \mathrm{mg}$ & $7 / 17$ & $13.3(6.5, U D)$ & & $0.39(0.15,0.99)$ & \\
\hline \multicolumn{6}{|c|}{ Amongst patients on $30 \mathrm{mg}$ starting dose: } \\
\hline \multicolumn{6}{|l|}{ Brain metastasis } \\
\hline No & $10 / 35$ & UD & 0.007 & 1 & 0.010 \\
\hline Yes & $13 / 23$ & $5.3(3.1,10.7)$ & & $2.96(1.29,6.79)$ & \\
\hline \multicolumn{6}{|c|}{ Amongst patients on $40 \mathrm{mg}$ starting dose: } \\
\hline \multicolumn{6}{|l|}{ Brain metastasis } \\
\hline No & $30 / 44$ & $15.0(10.8,22.1)$ & 0.567 & 1 & 0.558 \\
\hline Yes & $7 / 17$ & $13.3(6.5, \mathrm{UD})$ & & $0.79(0.34,1.80)^{a}$ & \\
\hline
\end{tabular}

PFS Progression-free survival, NA Not applicable, UD Undefined

${ }^{a}$ Non-proportional hazards

${ }^{\mathrm{b}}$ One patient had a starting dose of $20 \mathrm{mg}$. This patient was excluded

demonstrated that significant effect of afatinib loading dose (40 mg vs $30 \mathrm{mg}$ OD) on PFS was present only in patients with baseline brain metastases, and not amongst those without brain metastases prior to afatinib initiation - a provocative finding suggesting afatinib dose effect on BM. To the best of our knowledge, this study is the first to demonstrate a difference on outcomes of BM+ patients with different starting doses of afatinib.

Conventionally, WBRT is considered the standard treatment for BM, especially for multiple and symptomatic BM. Although $\mathrm{BM}+$ patients in the $40 \mathrm{mg}$ group were more likely to have undergone WBRT prior to 
Table 3 Comparison of characteristics between BM+ patients on $30 \mathrm{mg}$ and $40 \mathrm{mg}$ starting dose. Comparing the clinical characteristics of patients with brain metastases who started on $30 \mathrm{mg}$ OD vs $40 \mathrm{mg}$ OD of afatinib

\begin{tabular}{|c|c|c|c|}
\hline Characteristic & $\begin{array}{l}\text { Starting dose } 30 \mathrm{mg} \text {, } \\
\mathrm{n}(\%)\end{array}$ & $\begin{array}{l}\text { Starting dose } 40 \mathrm{mg} \text {, } \\
\mathrm{n}(\%)\end{array}$ & $p$-value \\
\hline \multicolumn{4}{|l|}{ Age at diagnosis, years } \\
\hline Median (range) & $62(47-78)$ & $58(26-76)$ & 0.299 \\
\hline$<65$ & $15(60.0)$ & $12(70.6)$ & 0.482 \\
\hline$\geq 65$ & $10(40.0)$ & $5(29.4)$ & \\
\hline \multicolumn{4}{|l|}{ Sex } \\
\hline Female & $16(64.0)$ & $6(35.3)$ & 0.067 \\
\hline Male & $9(36.0)$ & $11(64.7)$ & \\
\hline \multicolumn{4}{|l|}{ ECOG at start of afatinib } \\
\hline $0-1$ & $20(80.0)$ & $14(82.4)$ & 1.000 \\
\hline $2-3$ & $5(20.0)$ & $3(17.6)$ & \\
\hline \multicolumn{4}{|l|}{ Smoking history } \\
\hline Never & $18(72.0)$ & $13(76.5)$ & 1.000 \\
\hline Former/Current & $7(28.0)$ & $4(23.5)$ & \\
\hline \multicolumn{4}{|l|}{ Brain RT pre-afatinib } \\
\hline Yes & $12(48.0)$ & $14(82.4)$ & 0.024 \\
\hline No & $13(52.0)$ & $3(17.6)$ & \\
\hline \multicolumn{4}{|l|}{ Brain RT post-afatinib } \\
\hline Yes & $4(16.0)$ & $3(17.6)$ & 1.000 \\
\hline No & $21(84.0)$ & $14(82.4)$ & \\
\hline \multicolumn{4}{|l|}{ EGFR mutation type } \\
\hline Exon 19 deletion & $15(62.5)$ & $9(52.9)$ & 0.019 \\
\hline Exon 20 insertion & $1(4.2)$ & 0 & \\
\hline Exon 21 L858R & $3(12.5)$ & $8(47.1)$ & \\
\hline Double mutation & $5(20.8)$ & 0 & \\
\hline Unknown & 1 & 0 & \\
\hline \multicolumn{4}{|l|}{ Site of progression ${ }^{a}$} \\
\hline CNS & $7(63.6)$ & $3(30.0)$ & 0.198 \\
\hline Systemic & $4(36.4)$ & $7(70.0)$ & \\
\hline \multicolumn{4}{|l|}{ No PD / unknown: } \\
\hline Still on afatinib & 5 & 2 & \\
\hline Went on 2nd line & 3 & 4 & \\
\hline No scans / no PD recorded & 4 & 1 & \\
\hline FU at other hospital & 2 & 0 & \\
\hline \multicolumn{4}{|l|}{ Afatinib dose at PD, mg } \\
\hline 20 & $2(18.2)$ & $1(10.0)$ & 0.270 \\
\hline 30 & $9(81.8)$ & $6(60.0)$ & \\
\hline 40 & 0 & $3(30.0)$ & \\
\hline No PD / unknown & 14 & 7 & \\
\hline
\end{tabular}

Note: Unknown data were not included in the calculation of percentages and $p$-values

${ }^{a}$ CNS PD: brain. Systemic PD: lung, bone/spine, liver, mediastinal LN, malignant pericardial effusion, nodes, pleura

${ }^{b}$ Note that there were 9 patients $(5 \mathrm{on} 30 \mathrm{mg}$ and 4 on $40 \mathrm{mg}$ ) who were still on afatinib at data cut-off. Dose intensity was calculated up to last follow-up date

for these patient 
Table 4 Multivariable model of afatinib starting dose and WBRT pre afatinib on PFS in BM+ patients at start of afatinib. The relationship between starting dose, WBRT pre-afatinib and PFS in patients with BM shown in a multivariable model

\begin{tabular}{lll}
\hline Multivariable analysis & Hazard ratio $(95 \% \mathrm{Cl})$ & $p$-value \\
\hline $\begin{array}{ll}\text { Brain RT pre-afatinib } \\
\text { No }\end{array}$ & 1 & \\
Yes & $2.79(0.93,8.35)$ & 0.062 \\
Starting dose & & \\
$30 \mathrm{mg}$ & 1 & 0.006 \\
$40 \mathrm{mg}$ & $0.22(0.07,0.67)$ & \\
\hline
\end{tabular}

afatinib initiation as compared to the $30 \mathrm{mg}$ group, it is noteworthy that starting dose remained significantly associated with PFS amongst patients who had WBRT before commencing afatinib, and also in multivariable analysis controlling for effect of WBRT. Moreover, patients who started on $40 \mathrm{mg}$ tended to be less likely to progress intracranially than those on $30 \mathrm{mg}$ dose, although not statistically significant due to small numbers. This effect was observed despite the frequency of dose reductions observed, and potentially represents how initial afatinib dose may impact on CNS control in these patients. This corroborates the findings of a competing risk analysis for progression of the LUX-Lung 3, 6, and 7 trials, that the hazard ratio for development of brain metastases as a site of progression was lower for afatinib compared to the control arms, providing another separate validation of the efficacy of afatinib as a brain-penetrant EGFR TKI [15].

The benefit of dose of afatinib on CNS metastases may be driven by the peak plasma concentrations attained, with initial phase I studies showing significant difference in $\mathrm{C}_{\max }$ (the maximum concentration of drug achieved after administration) when comparing 40 vs 30 mg [16]. In a small case series, Hochmair et al. reported in patients with multiple, symptomatic BM who declined WBRT, afatinib alone could achieve complete intracranial remission [17]. Two other studies also demonstrated effective CNS penetrance of afatinib - a Japanese one with cerebrospinal fluid (CSF) pharmacokinetic data with first-line afatinib treatment [18], and another German series demonstrating CNS activity in patients with $\mathrm{BM}$ progressing on first-generation TKIs [6]. Additional studies directed at overcoming CNS treatment failure include high-dose gefitinib and erlotinib given in a pulsatile manner, highlighting the importance of $\mathrm{C}_{\max }$ on intracranial responses $[19,20]$.

The main limitations of the current study include the small sample size and retrospective nature of the study, challenging the ability to draw definitive conclusions particularly with regards to afatinib dose effect on patterns of disease progression in $\mathrm{BM}+$ patients. Notwithstanding this, our findings highlight the potential importance of $\mathrm{C}_{\max }$ in control of brain metastases. This has significant implications on future studies in oncogene-driven NSCLC, where CNS metastases are a common reason for

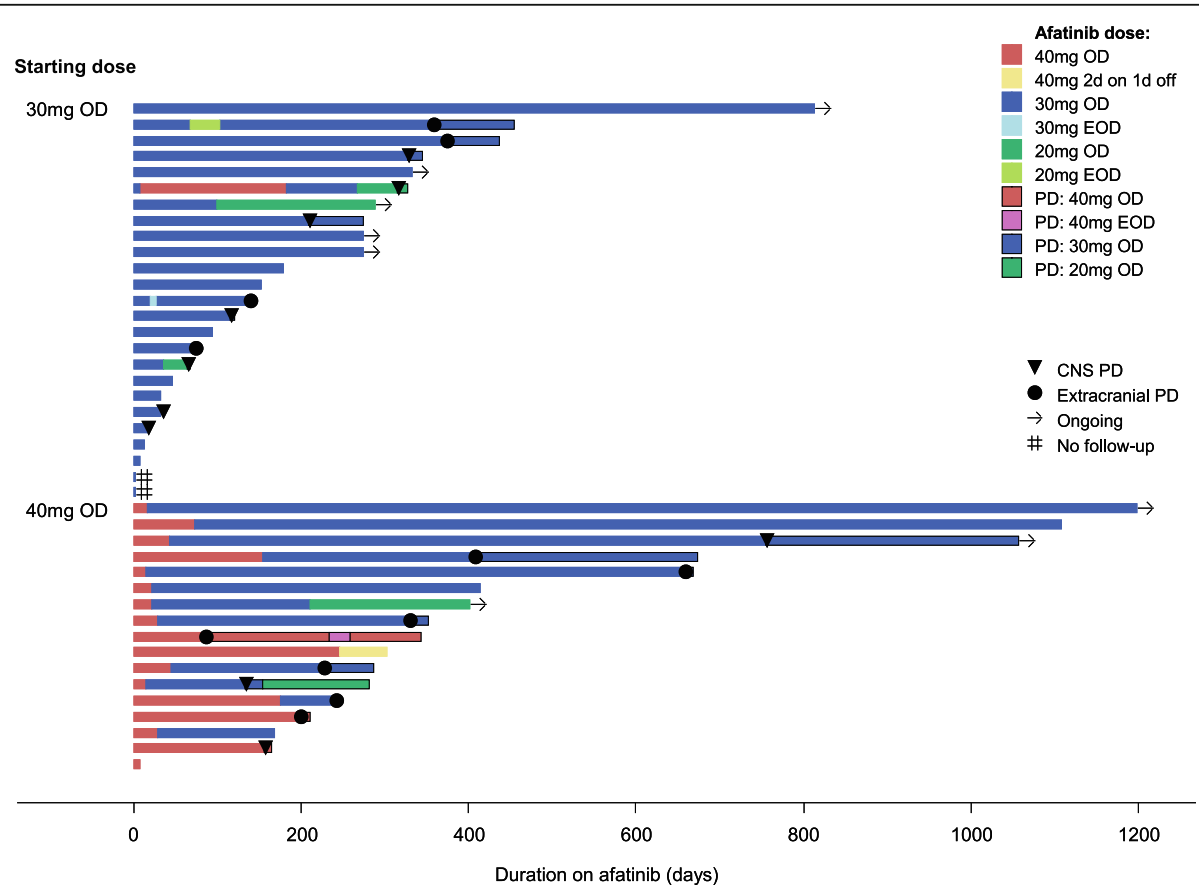

Fig. 1 Swimmer plot on dose intensity of afatinib in BM+ patients. Individual swimmer plots for each patient with BM and started on 30 mg OD vs $40 \mathrm{mg}$ OD afatinib, depicting duration and time of intracranial and extracranial disease progression (PD) on different doses of afatinib 
Table 5 Interaction between brain metastasis and afatinib starting dose in PFS. The interaction effect of brain metastasis and starting dose of afatinib (40 mg vs $30 \mathrm{mg}$ OD) in PFS of patients shown in a multivariable model

\begin{tabular}{|c|c|c|c|}
\hline & No. of events / patients & $\begin{array}{l}\text { Hazard ratio } \\
(95 \% \mathrm{Cl})\end{array}$ & $p$-value \\
\hline Brain metastasis; starting dose & $60 / 119$ & & \\
\hline Brain mets; $40 \mathrm{mg}$ & & 1 & \\
\hline Brain mets; $30 \mathrm{mg}$ & & $3.73(1.45,9.61)$ & 0.006 \\
\hline No brain mets; 40 mg & & $1.29(0.57,2.96)$ & 0.542 \\
\hline \multirow[t]{2}{*}{ No brain mets; $30 \mathrm{mg}$} & & $1.21(0.45,3.23)$ & 0.711 \\
\hline & & p-value of brain mets-starting dose interaction: & 0.020 \\
\hline \multicolumn{4}{|c|}{ Amongst never smokers with exon 19 deletion or L858R mutation: } \\
\hline Brain metastasis; starting dose & $37 / 84$ & & \\
\hline Brain mets; $40 \mathrm{mg}$ & & 1 & \\
\hline Brain mets; 30 mg & & $5.23(1.42,19.28)$ & 0.013 \\
\hline No brain mets; $40 \mathrm{mg}$ & & $1.67(0.57,4.87)$ & 0.345 \\
\hline \multirow[t]{2}{*}{ No brain mets; 30 mg } & & $1.10(0.29,4.20)$ & 0.884 \\
\hline & & p-value of brain mets-starting dose interaction: & 0.011 \\
\hline
\end{tabular}

treatment failure and optimal CNS control remains an unmet need. A phase $1 \mathrm{~b}$ study recently demonstrated the feasibility and tolerability of high-dose intermittent (HDI) afatinib (3 days every 14 days) achieving high plasma concentrations of afatinib, but focused on heavily pretreated advanced T790 M+ NSCLC [21]. Albeit modest activity (7.7\%) with HDI afatinib, this may be a potential strategy for patients with CNS metastases. To this end, we have initiated a prospective dose-finding study of continuous (40 mg OD) vs. intermittent high-dose (HDI) afatinib (160 $\mathrm{mg} \times 3$ days every 2 weeks) on CNS metastases and leptomeningeal disease in patients with advanced refractory EGFRm+ NSCLC (NCT03711422) to address control of
CNS metastases. In this prospective study we will also be assessing the plasma and CSF drug ratios from the 2 different dosing schedules to determine pharmacokinetic efficacy of HDI afatinib on CNS control. Future prospective studies exploring alternative TKI dosing schedules such as intermittent dosing with $40 \mathrm{mg} \mathrm{OD}$, so as to maintain $\mathrm{C}_{\max }$ while circumventing toxicities from continuous dosing of afatinib, are warranted to specifically address the impact of drug exposure on durability of CNS disease control.

\section{Conclusion}

We demonstrated that in advanced EGFR-mutant NSCLC patients with brain metastases, starting dose of
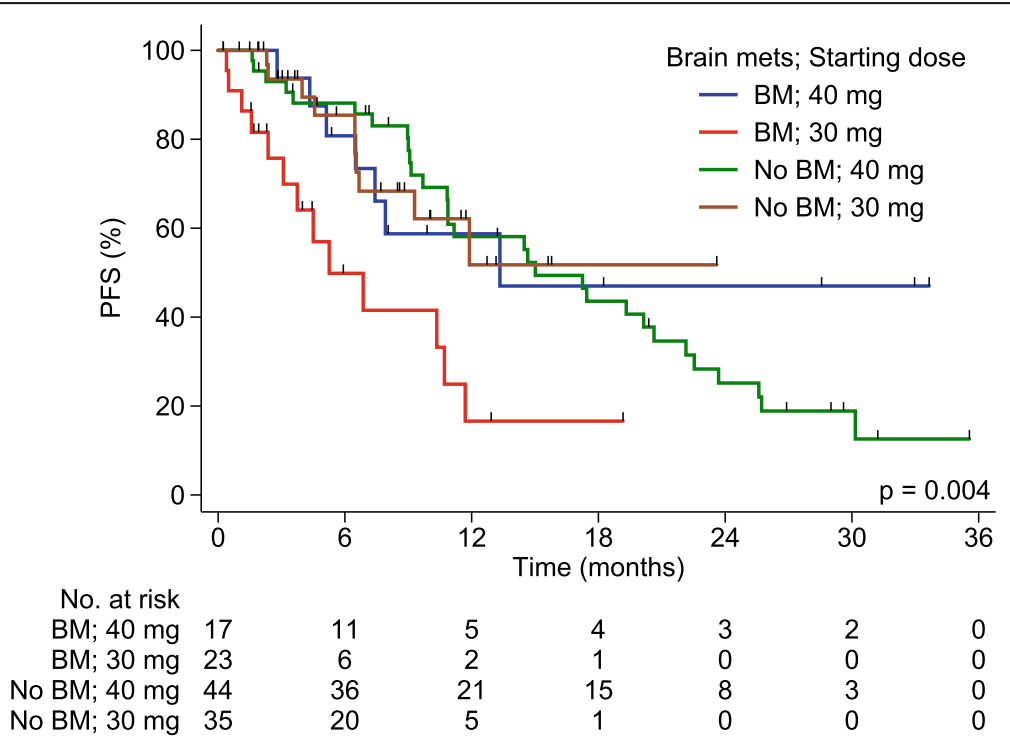

11
6
36
20

$\begin{array}{cc}5 & 4 \\ 2 & 1 \\ 21 & 15 \\ 5 & 1\end{array}$

$\begin{array}{cc}4 & 3 \\ 1 & 0 \\ 15 & 8 \\ 1 & 0\end{array}$

$\begin{array}{ll}2 & 0 \\ 0 & 0 \\ 3 & 0 \\ 0 & 0\end{array}$

Fig. 2 Kaplan-Meier (KM) plot of PFS showing the interaction between BM and starting dose of afatinib. KM plot showing interaction between presence of BM at start of treatment and starting dose of afatinib in our cohort 
afatinib at $40 \mathrm{mg} /$ day led to better clinical outcomes compared to those who had reduced starting dose of 30 $\mathrm{mg}$ /day, possibly due to effects of a higher $\mathrm{C}_{\max }$ on CNS control. These results also lend support to the CNS activity from afatinib. Moving forward, further elucidation and validation of afatinib dose effect specifically on BM control with concomitant plasma $\mathrm{C}_{\max }$ testing in a larger prospective study will certainly be crucial.

\section{Abbreviations}

BM: Brain metastases; $C_{\text {max }}$ : Maximum concentration of drug; CNS: Central nervous system; CR: Complete response; CSF: Cerebrospinal fluid; EGFR: Epidermal growth factor receptor; EGFRm+: EGFR-mutant; HER: Panhuman epidermal growth factor receptor; NSCLC: Non-small cell lung cancer; OD: Once daily; PD: Progressive disease; PFS: Progression free survival; RR: Response rate; TKI: Tyrosine-kinase inhibitor; WBRT: Whole brain radiotherapy

\section{Acknowledgements}

Study data were collected and managed using REDCap electronic data capture tools hosted at National Cancer Centre Singapore. This work was also supported by the Duke-NUS Khoo Scholars Programme.

\section{Funding}

This work was funded by the National Medical Research Council (Singapore) (NMRC) through the Translational and Clinical Research Program "Non-Small Cell Lung Cancer: Targeting Cancer Stem Cell and Drug Resistance" (NMRC/ TCR/007-NCC/2013). This work was also funded in part by Singapore Millenium Foundation, the Trailblazer Foundation Ltd., and the National Cancer Centre Research Fund that jointly supported the infrastructure of the Lung Cancer Consortium Singapore.

\section{Availability of data and materials}

All data generated or analyzed during this study are included in this published article.

\begin{abstract}
Authors' contributions
WLT contributed to the drafting of this manuscript, acquisition of data, analysis and interpretation of the data. QSN contributed to the study conception and design, acquisition of data and interpretation of the findings. CL contributed to the statistical analysis and interpretation of data. EHT, CKT, MKA, RK and AJ contributed to acquisition of data and interpretation of data. DSWT contributed to acquisition of data, analysis and interpretation of the findings, and review of the manuscript. DWTL contributed to the study design, analysis of the data and interpretation of the findings, and review of the manuscript. All authors have read and approved the submission of the final manuscript.
\end{abstract}

\section{Ethics approval and consent to participate}

A written informed consent to participate was obtained from each of the patients under our Lung Cancer Consortium Singapore (LCCS) data-base. This study was approved by Centralized Institutional Review Board (CIRB), Singapore (CIRB 2007/444/B). Patient data were de-identified and anonymized before analysis.

\section{Consent for publication}

Not applicable.

\section{Competing interests}

Dr. WT Lim reports grants from BMS, honoraria for advisory boards from MSD, Boehringer-Ingelheim, and Takeda, outside the submitted work; Dr. DSW Tan reports grants and honoraria for advisory boards and other from Novartis, Bayer, Boehringer Ingelheim, Merck, AstraZeneca, BMS, Roche and grants from GSK, outside the submitted work; Dr. QS Ng reports being in the Advisory board of Boehringer-Ingelheim. The remaining authors declare no potential conflict of interest.

\section{Publisher's Note}

Springer Nature remains neutral with regard to jurisdictional claims in published maps and institutional affiliations.

\section{Author details}

${ }^{1}$ Division of Medical Oncology, National Cancer Centre Singapore, Singapore, Singapore. ${ }^{2}$ Clinical Trials \& Epidemiological Sciences, National Cancer Centre Singapore, Singapore, Singapore. ${ }^{3}$ Genome Institute of Singapore, A*STAR, Singapore, Singapore. ${ }^{4}$ Institute of Molecular and Cell Biology, A*STAR, Singapore, Singapore.

Received: 30 August 2018 Accepted: 20 November 2018 Published online: 03 December 2018

\section{References}

1. Pao W, Miller V, Zakowski M, Doherty J, Politi K, Sarkaria I, Singh B, Heelan R, Rusch $V$, Fulton L, et al. EGF receptor gene mutations are common in lung cancers from "never smokers" and are associated with sensitivity of tumors to gefitinib and erlotinib. Proc Natl Acad Sci U S A. 2004;101(36):13306-11.

2. Tan DS, Yom SS, Tsao MS, Pass HI, Kelly K, Peled N, Yung RC, Wistuba II, Yatabe $Y$, Unger $M$, et al. The International Association for the Study of Lung Cancer consensus statement on optimizing management of EGFR mutation-positive non-small cell lung Cancer: status in 2016. J Thorac Oncol. 2016;11(7):946-63.

3. Schuler M, Wu YL, Hirsh V, O'Byrne K, Yamamoto N, Mok T, Popat S, Sequist LV, Massey D, Zazulina V, et al. First-line Afatinib versus chemotherapy in patients with non-small cell lung Cancer and common epidermal growth factor receptor gene mutations and brain metastases. J Thorac Oncol. 2016; 11(3):380-90.

4. Iuchi T, Shingyoji M, Itakura M, Yokoi S, Moriya Y, Tamura H, Yoshida Y, Ashinuma H, Kawasaki K, Hasegawa $Y$, et al. Frequency of brain metastases in non-small-cell lung cancer, and their association with epidermal growth factor receptor mutations. Int J Clin Oncol. 2015;20(4):674-9.

5. Jain A, Lim C, Gan EM, Ng DZ, Ng QS, Ang MK, Takano A, Chan KS, Tan WM, Kanesvaran R. Impact of smoking and brain metastasis on outcomes of advanced EGFR mutation lung adenocarcinoma patients treated with first line epidermal growth factor receptor tyrosine kinase inhibitors. PLoS One. 2015;10(5):e0123587

6. Hoffknecht $P$, Tufman $A$, Wehler $T$, Pelzer $T$, Wiewrodt $R$, Schütz $M$, Serke M, Stöhlmacher-Williams J, Märten A, Huber RM. Efficacy of the irreversible ErbB family blocker afatinib in epidermal growth factor receptor (EGFR) tyrosine kinase inhibitor (TKI)-pretreated non-small-cell lung cancer patients with brain metastases or leptomeningeal disease. J Thorac Oncol. 2015;10(1):156-63.

7. Yang J-H, Sequist L, Zhou C, Schuler M, Geater S, Mok T, Hu C-P, Yamamoto $\mathrm{N}$, Feng J, O'byrne K. Effect of dose adjustment on the safety and efficacy of afatinib for EGFR mutation-positive lung adenocarcinoma: post hoc analyses of the randomized LUX-lung 3 and 6 trials. Ann Oncol. 2016;27(11):2103-10.

8. Lynch TJ, Bell DW, Sordella R, Gurubhagavatula S, Okimoto RA, Brannigan BW, Harris PL, Haserlat SM, Supko JG, Haluska FG, et al. Activating mutations in the epidermal growth factor receptor underlying responsiveness of nonsmall-cell lung Cancer to Gefitinib. N Engl J Med. 2004;350(21):2129-39.

9. Lopez-Rios F, Angulo B, Gomez B, Mair D, Martinez R, Conde E, Shieh F, Tsai J, Vaks J, Current R, et al. Comparison of molecular testing methods for the detection of EGFR mutations in formalin-fixed paraffin-embedded tissue specimens of non-small cell lung cancer. J Clin Pathol. 2013;66(5):381-5.

10. Pirker R, Herth FJ, Kerr KM, Filipits M, Taron M, Gandara D, Hirsch FR, Grunenwald D, Popper H, Smit E, et al. Consensus for EGFR mutation testing in non-small cell lung cancer: results from a European workshop. J Thorac Oncol. 2010;5(10):1706-13.

11. Lindeman NI, Cagle PT, Beasley MB, Chitale DA, Dacic S, Giaccone G, Jenkins RB, Kwiatkowski DJ, Saldivar JS, Squire J, et al. Molecular testing guideline for selection of lung cancer patients for EGFR and ALK tyrosine kinase inhibitors: guideline from the College of American Pathologists, International Association for the Study of Lung Cancer, and Association for Molecular Pathology. J Thorac Oncol. 2013;8(7):823-59.

12. Sequist LV, Yang JC, Yamamoto N, O'Byrne K, Hirsh V, Mok T, Geater SL, Orlov S, Tsai CM, Boyer M, et al. Phase III study of afatinib or cisplatin plus pemetrexed in patients with metastatic lung adenocarcinoma with EGFR mutations. J Clin Oncol. 2013;31(27):3327-34. 
13. Wu Y-L, Zhou C, Hu C-P, Feng J, Lu S, Huang Y, Li W, Hou M, Shi JH, Lee KY, et al. Afatinib versus cisplatin plus gemcitabine for first-line treatment of Asian patients with advanced non-small-cell lung cancer harbouring EGFR mutations (LUX-lung 6): an open-label, randomised phase 3 trial. Lancet Oncol. 2014;15(2):213-22.

14. Yang C-J, Tsai M-J, Hung J-Y, Lee M-H, Tsai Y-M, Tsai Y-C, Hsu J-F, Liu T-C, Huang M-S, Chong I-W. The clinical efficacy of Afatinib $30 \mathrm{mg}$ daily as starting dose may not be inferior to Afatinib $40 \mathrm{mg}$ daily in patients with stage IV lung adenocarcinoma harboring exon 19 or exon 21 mutations. BMC Pharmacol Toxicol. 2017;18(1):82.

15. Girard N. Optimizing outcomes in EGFR mutation-positive NSCLC: which tyrosine kinase inhibitor and when? Future Oncol. (London, England). 2018; 14(11):1117-32.

16. Yap TA, Vidal L, Adam J, Stephens P, Spicer J, Shaw H, Ang J, Temple G, Bell S, Shahidi M. Phase I trial of the irreversible EGFR and HER2 kinase inhibitor BIBW 2992 in patients with advanced solid tumors. J Clin Oncol. 2010;28(25): 3965-72.

17. Hochmair M, Holzer S, Burghuber OC. Complete remissions in afatinibtreated non-small-cell lung cancer patients with symptomatic brain metastases. Anti-Cancer Drugs. 2016;27(9):914-5.

18. Tamiya A, Tamiya M, Nishihara T, Shiroyama T, Nakao K, Tsuji T, Takeuchi N, Isa S-I, Omachi N, Okamoto N. Cerebrospinal fluid penetration rate and efficacy of Afatinib in patients with EGFR mutation-positive non-small cell lung Cancer with leptomeningeal Carcinomatosis: a multicenter prospective study. Anticancer Res. 2017;37(8):4177-82.

19. Zhu Y, Du Y, Liu H, Ma T, Shen Y, Pan Y. Study of efficacy and safety of pulsatile administration of high-dose gefitinib or erlotinib for advanced non-small cell lung cancer patients with secondary drug resistance: a single center, single arm, phase II clinical trial. Thorac Cancer. 2016;7(6):663-9.

20. Grommes C, Oxnard GR, Kris MG, Miller VA, Pao W, Holodny Al, Clarke JL, Lassman AB. "Pulsatile" high-dose weekly erlotinib for CNS metastases from EGFR mutant non-small cell lung cancer. Neuro-Oncology. 2011;13(12): 1364-9.

21. Camidge DR, Sequist LV, Janne PA, Weickhardt AJ, Dowling ES, Alicea J, Fan J, Oxnard GR. Phase lb study of high-dose intermittent Afatinib in patients with advanced solid tumors. Clin Lung Cancer. 2018;19(5):e655-65.

Ready to submit your research? Choose BMC and benefit from:

- fast, convenient online submission

- thorough peer review by experienced researchers in your field

- rapid publication on acceptance

- support for research data, including large and complex data types

- gold Open Access which fosters wider collaboration and increased citations

- maximum visibility for your research: over $100 \mathrm{M}$ website views per year

At $\mathrm{BMC}$, research is always in progress.

Learn more biomedcentral.com/submissions 